\title{
Mountain Natural Resources
}

Discussion Paper Series No. MNR 98/2

Integrating Geomatics and

Participatory Techniques for

Community Forest Management

Case Studies from the Yarsha Khola Watershed,

Dolakha District, Nepal

Gavin H. Jordan

Bhuban Shrestha

International Centre for Integrated Mountain Development

Kathmanda, Nepal

1998 
Copyright (c) 1998

ISSN $1024-7556$

International Centre for Integrated Mountain Development

All rights reserved

\section{Published by}

International Centre for Integrated Mountain Development

G.P.O. Box 3226

Kathmandu, Nepal

Typesetting at ICIMOD Publications' Unit

The views and interpretations in this paper are those of the author(s). They are not attributable to the International Centre for Integrated Mountain Development (ICIMOD) and do not imply the expression of any opinion concerning the legal status of any country, territory, city or area of its authorities, or concerning the delimitation of its frontiers or boundaries. 


\section{Integrating Geomatics and Participatory Techniques for Community Forest Management}

Case Studies from the Yarsha Khola Watershed, Dolakha District, Nepal

Gavin H. Jordan

Bhuban Shrestha

MNR Series No. $98 / 2$

Gavin Jordan works for the Department of Environmental and Geographical Sciences, Manchester Metropolitan University, and is a Research Associate of the Forest Products' Research Centre, Buckinghamshire College, UK.

Bhuban Shrestha works for ICIMOD and is the GIS Land-use Specialist for the PARDYP Project, Nepal

International Centre for Integrated Mountain Development

Kathmandu, Nepal 


\section{Preface}

The work described in this publication has been conducted as part of the People and Resource Dynamics' Project (PARDYP), implemented by ICIMOD. PARDYP is a threeyear watershed management research and development project in the fields of:

- cooperative rural participation,

- hydrology and meteorology research,

- soil erosion and fertility studies,

- conservation activities,

- rehabilitation of degraded areas, and

- agronomic and horticultural initiatives

PARDYP operates in five watersheds in four of ICIMOD's partner countries - Pakistan, India, Nepal, and China. It approaches watershed dynamics and research in a holistic, interdisciplinary, and participatory manner.

The goal of PARDYP is to improve the understanding of environmental and socioeconomic processes associated with degradation and rehabilitation of mountain ecosystems and to generate wider adoption and adaptation of proposed solutions by stakeholders in the Hindu Kush-Himalayas $(\mathrm{HKH})$.

By providing a basic understanding of the processes concerned with natural resource degradation, it seeks to recommend proven strategies and programmes for community and farm-based rehabilitation of the natural resources in the $\mathrm{HKH}$ region.

PARDYP is funded by the Swiss Agency for Development and Cooperation (SDC), the International Development Research Centre (IDRC - Canada), and ICIMOD. It is actively supported by institutions in both the collaborating regional countries and further afield, notably the University of British Columbia, The University of Bern, and the Swiss National Hydrological and Geological Survey. 


\section{Acknowledgements}

The authors would like to acknowledge the following for their help and assistance in this study.

Diwakar Maskey, Agro-forester for PARDYP, for his invaluable assistance with the field work component. All the staff at the PARDYP field office, Maina Pokhri. Pravakar Bickram Shah, Country Coordinator, PARDYP, for supporting and assessing with logistics. The range post and DFO staff, who helped with this study, particularly Mr. Jhirel. Members of the Forest User Groups who assisted with the participatory work and conducted the forest inventories. Steve Hunt and Mr. Prajapati of NACFP, Robin Ostravee of SDC, and Richard Mather, working for NUKCFP, for their advice. Special thanks to Jeannette Gurung, Gender Specialist, and Anupam Bhatia, ICIMOD, for reviewing the paper from a forestry and community forestry aspect, respectively.

Gavin Jordan would also like to thank Egbert Pelinck, Director General of ICIMOD and Richard Allen, PARDYP Coordinator, for the opportunity to conduct this research with the PARDYP Nepal team. 


\section{Abstract}

There is a growing need for forest resource information in community forestry to provide baseline data enabling changes in the resource to be assessed. Traditional methods of forest resource assessment are not appropriate for community forestry owing to the time and expense involved and their focus on timber production.

This paper shows how recent geomatics' technology can be used in conjunction with participatory techniques to provide a framework for low cost, appropriate technology forest resource assessment. The role and value of a variety of different approaches are evaluated by using case studies as examples.

The use of geomatics in a participatory context has great potential for community forest resource assessment in providing basic spatial data for management purposes rapidly and effectively, and by acting as a facilitation tool. 


\section{Table of Contents}

Preface

Acknowledgements

Abstract

Part 1: Setting and Methodology

1.1 Introduction

1.2 Aims and Objectives

1.3 An Outline of the Methodology

Overview

The Framework for Resource Assessment

Initial Participatory Session

Aerial Photographs

Global Positioning Systems (GPS)

Geographical Information Systems (GIS)

1.4 The Study Area

Location

Land Use

Population

Part 2: Case Studies from the Yarsha Khola Watershed

2.1 Introduction to the Case Studies

Background on the FUG and Their Forests

2.2 An Example of a Participatory Session

2.3 Aerial Photo Session

2.4 Using GPS

2.5 Information Analysis and Dissemination: The Role of GIS

2.6 Discussion

Key Issues

Addressing the Aims

2.7 Conclusions

Limitations

Further Work 